\title{
Evaluation of the Working Parameters of a Series-Hybrid Tractor under the Soil Work Conditions
}

\author{
Ugnè Koletė MEDŽEVEPRYTE்*, Rolandas MAKARAS, Vaidas LUKOŠEVIČIUS, Artūras KERŠYS
}

\begin{abstract}
The economy sectors of transport and agriculture are among the major contributors to environmental pollution. Certain environmental solutions are increasingly implemented in agriculture in order to reduce the pollution. Among these solutions are the alternative types of fuel and powertrain used in the heavy-duty vehicles, although their use is rather fragmented. This paper investigates the possibilities for the use of the hybrid drive in agricultural vehicles during the soil cultivation process by simulating the actual work conditions. The numerical model of the medium power tractor with CNG ICE and a series-hybrid setup was created, and the simulations were performed in the Matlab-Simscape environment. Evaluation of the hybrid drive power demand for conventional field works was performed. Energy loss and efficiency of the drive were calculated for different work modes. Fuel costs and run time on one cylinder were evaluated and the variation in the run time in view of the efficiency of the engine working points was determined. The designed model may be used for development of the control algorithms for hybrid drives and improvement of the efficiency thereof. During the investigations, drive management was found to have considerable influence on the fuel costs.
\end{abstract}

Keywords: agricultural vehicle; CNG; heavy-duty hybrid; hybrid powertrain; series-hybrid efficiency; power demand

\section{INTRODUCTION}

The recently increasing efforts to mitigate the greenhouse gas (GHG) emissions by transport have led to emergence of the pollution reduction programmes implemented across different regions. The supply of new models fitted with CNG internal combustion engines or hybrid drives offered by car manufacturers in the U.S. and Europe is anticipated to grow by up to $90 \%$ by the year 2050. CNG would be expected to basically replace the conventional petrol and diesel internal combustion engines (ICE) [1]. It is also projected that the use of biomethane, synthetic fuels and electrification would grow in heavyduty transport globally by the year 2050. Heavy-duty transport in China, North America, the EU is the largest contributor to the $\mathrm{CO}_{2}$ amounts. China anticipates minimizing this pollution by the year 2035. It is forecast that, by the year 2050, the U.S. will have implemented the clean freight transport mission, while the EU will have reached five-fold reduction in the $\mathrm{CO}_{2}$ amount, by use of alternative fuels and powertrains [2].

Although electrification of passenger cars has been discussed for a long time, and large supply of electrified cars has been reached on the market, electric and hybrid drives in heavy-duty vehicles remain largely at the stage of concepts. Due to their inefficiency for the work modes characteristic of long-distance or high-load towing vehicles and tractors, the types of hybrid and electric drives used widely in passenger cars are not suitable for the former. Hence, in order to electrify heavy-duty vehicles, the focus must be placed on other methods of electrification, wider use of gas-fuelled engines, optimisation of the powertrain management algorithms. A conventional electric drive used widely in passenger cars could fit short-distance (up to $50 \mathrm{~km}$ ) delivery vans which need to regularly enter low-emission zones [3]. Meanwhile, longer distances require additional systems and electric drive switching methods, at least, distance extension systems [4].

There is no such electrification system which would fit all types of vehicles. The influence of diverse electrification methods application in heavy-duty transport on the $\mathrm{CO}_{2}$ emissions throughout the life cycle of the vehicle is investigated [5]. Although the electric drive is the most efficient, it contributes to larger weight of the vehicle and requires more energy for the same work. Moreover, although the electric drive does not cause any pollution while in use, the general pollution it causes throughout the life cycle is greater than the still prevalent heavy-duty vehicles fitted with diesel engines. A hybrid vehicle with a petrol engine demonstrated the most favourable results during the investigation and could be considered as a compromise solution between mitigation of the pollution, vehicle weight, mobility, and drive efficiency. Carriers have also referred to mobility (long distance on one full cylinder/charge and fast filling/charging) as the key criterion in selection of the vehicle, and, although the pollution-related taxes depend on the fleet used, pollution is the last factor taken into consideration when selecting the vehicle [6].

Until present, the majority of studies of electric and hybrid drives have been related to energy management [7, 8]. Nonetheless, designing an energy management system for heavy-duty vehicles is a complicated task due to the constantly high-load nature of its use, meaning that appropriate efficiency is not always feasible with the hybrid drive [9].

Another important aspect is the choice of mechanical link - the transmission - for the hybrid drive. This determines the mechanical efficiency of the drive [10]. The following three types of delivery of the electric motor (EM) torque to the wheels are the most widely used in practice: electric motor connected directly; via a conventional gear reducer; via a planetary gear. The type of mechanical transmission also determines the drive management algorithms.

Driving conditions shall also be defined in determination of the hybrid drive efficiency. It is noted that the previous studies on heavy-duty vehicles employed an established driving cycle used in the tests but failed to account for actual driving conditions [8]. The researchers investigated a military heavy-duty series-hybrid vehicle with in-wheel electric motors to assess the hybrid drive efficiency and vehicle weight for the hybrid drive. It is very 
important to account for the work conditions in dealing with the heavy-duty vehicles, in particular, tractors, as the field works differ considerably from normal road driving conditions in terms of power demand.

The present study was performed to verify the possibilities for use of the series-hybrid drive in agricultural vehicle and its limitations under difficult field work conditions. Series-hybrid efficiency is defined by determining the most efficient work modes regarded to the power demands and fuel consumption.

\section{METHODOLOGY \\ 2.1 Hybrid Drive Setup}

Hybrid or electric drives are not used widely in agriculture where the vehicle is required to overcome high resistance of the environment (soil, implements). This study proposes such possibility by evaluating power demands and possibilities of the hybrid powertrains under shifting conditions, when no electrical energy reserve is available hence energy recovery in field operations is unlikely. This is a new method, as no consensus has been established yet regarding the methodology/cycle of investigation of the efficiency, energy costs and emissions of the heavy-duty hybrid vehicles.

Medium-power tractor ClaasXerion 3300 base was used for the investigation due to its frame structure, which is convenient for the setup. The tractor was retrofitted by the authors using the hybrid drive and compressed natural gas (CNG) engine. Series-hybrid concept was chosen for the hybrid heavy-duty vehicle. The power of the ICE, generator and electric motors was selected in view of the intended functions of the tractor. Components of the hybrid drive were selected. They were placed so as to make sure that distribution of mass on the axles is similar to the original: $53 / 47 \%$.

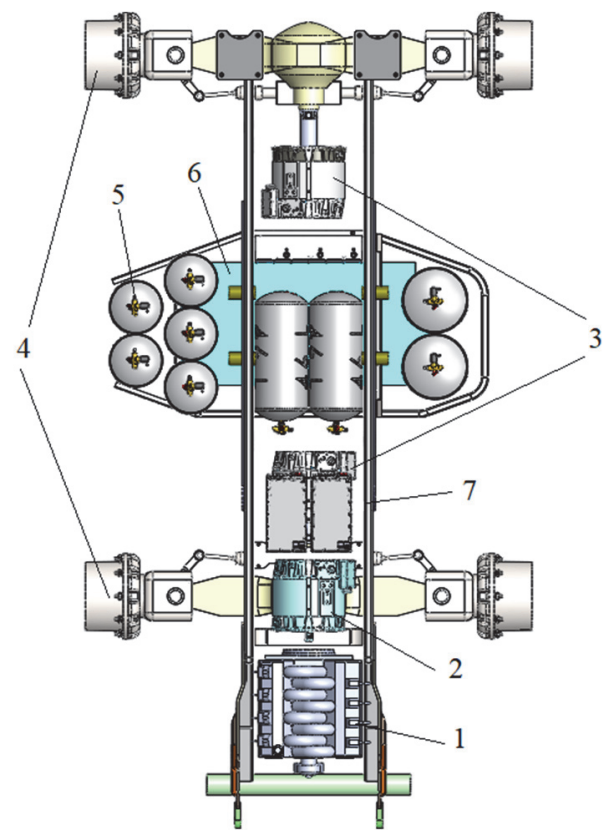

Figure 1 Series-hybrid scheme: 1 - CNG engine, 2 - alternator, 3 - electric motor, 4 - axle, 5 - CNG cylinders, 6 - battery, 7 - frame

$179 \mathrm{~kW}$ power and $638 \mathrm{Nm}$ torque gas engine was used. Type of gas: CNG. The ICE provided rotation of the $165 \mathrm{~kW}$ generator. This pair of components weighing 850 $\mathrm{kg}$ was placed in the front end of the tractor (Fig. 1). It supplied power to the 2 electric motors driving the axles, each electrical motor having the power of $100 \mathrm{~kW}$, torque $-740 \mathrm{Nm}$. In the hybrid drive, the electric motor is connected directly to the final drive without any additional drives, as this solution is expected to reduce the mechanical loss of the drive. The excess electrical power was stored in $352 \mathrm{~kg} 666 \mathrm{~V} 46 \mathrm{Ah}$ battery placed in the middle of the tractor, under the frame. The remaining space in the structure was occupied by $\mathrm{CNG}$ gas cylinders, total mass without fuel: $507 \mathrm{~kg}$. Gas cylinder capacity: $278 \mathrm{~kg}$ of the fuel mass. The wheel rolling radius of the tractor wheels used: $1 \mathrm{~m}$, permissible wheel skidding: $15 \%$, final drive transmission gear ratio: 26. Hybrid tractor weight: 12500 $\mathrm{kg}$.

In view of the intended tractor functions, the working speeds, loads, soil conditions were chosen. The main activities performed in the field are ploughing, harrowing, cultivation, and the defined working speed range was 2.5 $\mathrm{m} / \mathrm{s}$ (for harrowing) to $3.5 \mathrm{~m} / \mathrm{s}$ (for cultivation). The tractor had the following implements attached: $5 \mathrm{~m}$ cultivator and 2.5 and $3.5 \mathrm{~m}$ ploughs. The working loads were chosen according to the resistance created by the implements: 20 $\mathrm{kN}$ (for cultivation at a low soil depth) to $80 \mathrm{kN}$ (for ploughing). The soil is viewed as a tilled (ploughed) field with the rolling resistance ratio 0.18 .

\subsection{Mathematical Model of the Hybrid Drive}

The power demand and efficiency of the drive were investigated using the mathematical model developed using the Matlab-Simscape application. The hybrid model was composed of mechanical, electrical and management components. The model system is presented in Fig. 2.

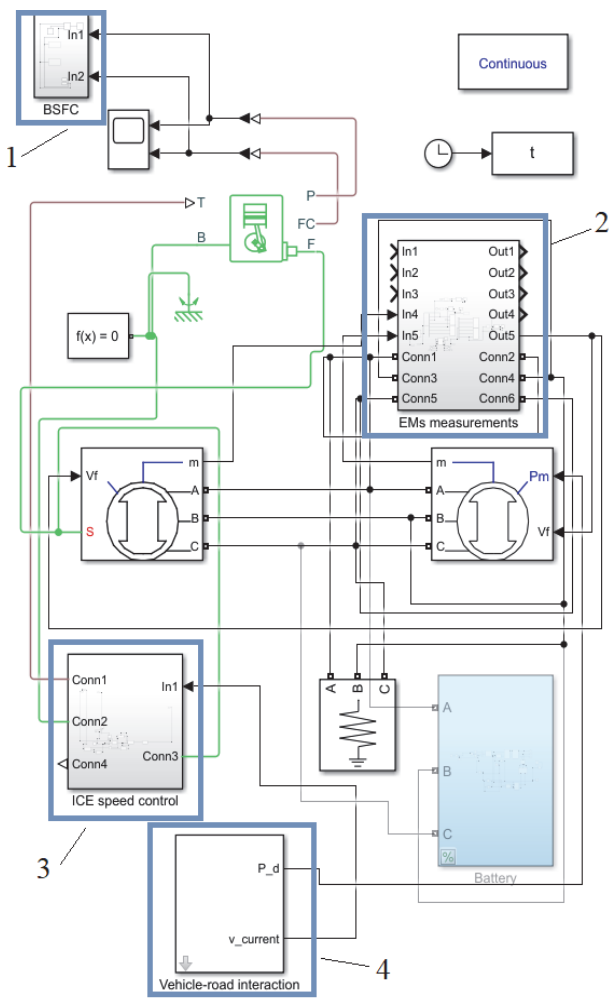

Figure 2 Simscape model of the hybrid heavy-duty vehicle (1 - specific fuel consumption calculation unit; 2 - electric motor measurement and management unit; 3 - ICE speed management unit; 4 - vehicle-environment interface unit) 
The gas-fuelled ICE is described by the power and torque curves, while specific fuel consumption - using the consumption map by rotational speed and torque. The ICE rotational speed is adjusted according to the speed reached by the vehicle and its energy consumption (Fig. 3) - the rotational speed is increased until the required generator output is reached to cover the energy consumption, e.g., until the working speed is reached, and then returns to nominal rotational speed.

The ICE is directly connected to the electric generator which delivers the energy to the electric motor. Nominal voltage of the two electric motors: $500 \mathrm{~V}$, frequency: 134 $\mathrm{Hz}$. EMs measurement unit was used for electric motor management and parameter monitoring.

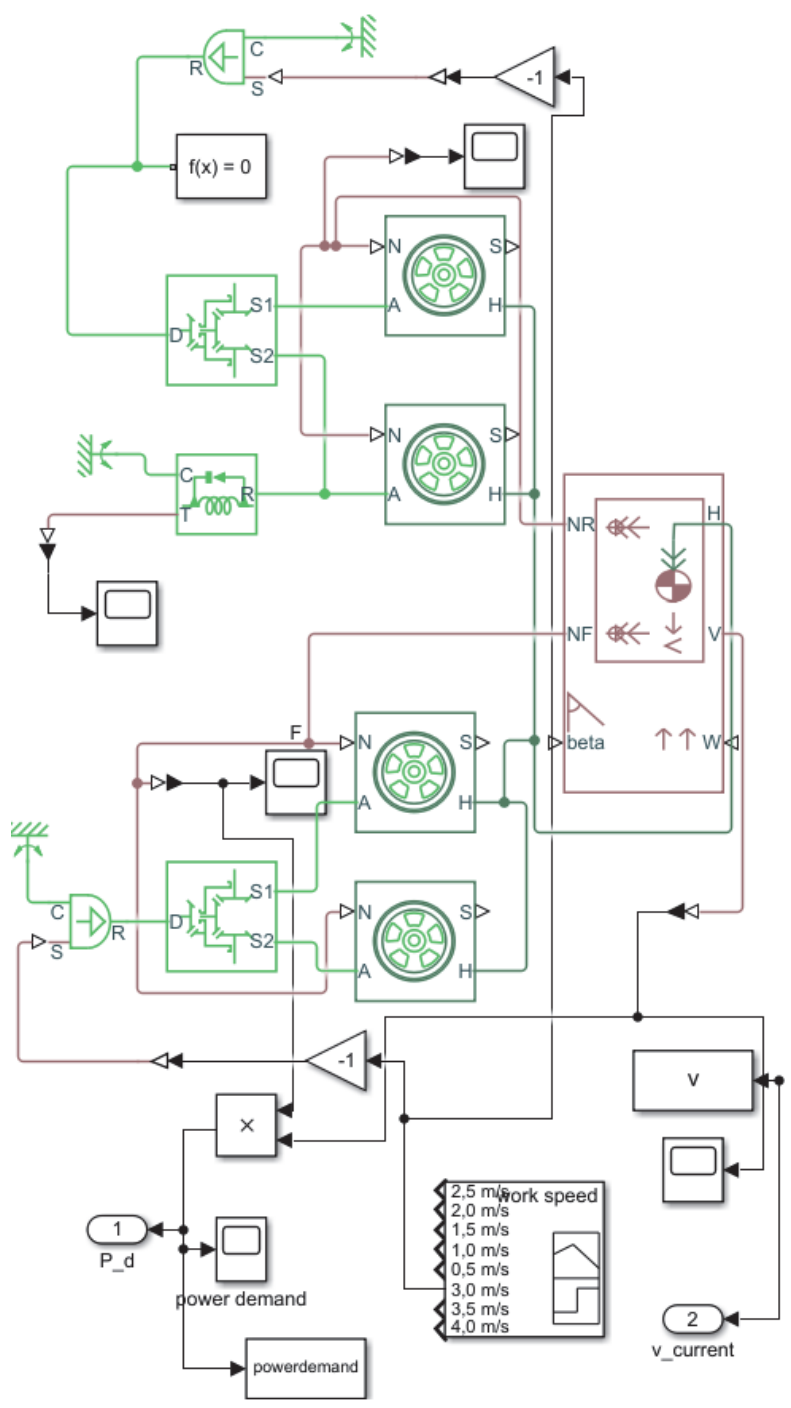

Figure 3 Vehicle-road interaction block

Tractor movement was controlled by the environment interface unit, which described the work conditions: rolling resistance ratio $f_{\text {roll }}=0.18$, working load varying from 20 $\mathrm{kN}$ to $80 \mathrm{kN}$ [11, 12], vehicle parameters: weight, weight distribution, skidding, air resistance ratios. Driving speed signal was introduced and formed as well. Driving speed was developed by moving from standstill at $0.5 \mathrm{~m} / \mathrm{s}^{2}$ acceleration up to the working speed. Three working speeds were used for the case investigated: $2.5 \mathrm{~m} / \mathrm{s}, 3.0 \mathrm{~m} / \mathrm{s}$ and $3.5 \mathrm{~m} / \mathrm{s}$ [13]. Power demand $P_{\text {EM }}$ used as the electric motor management signal was calculated according to the work mode. Output speed signal was used for adjustment of the ICE rotational speed.

\section{FINDINGS AND DISCUSSION}

The acceleration part in the management signal was used for determining the power in development of the working speed. The maximum power value during acceleration $P_{\mathrm{EM} \max }$ was recorded as soon as the working speed was reached at $0.5 \mathrm{~m} / \mathrm{s}^{2}$ acceleration.

The power demand of the electric motor for acceleration $P_{\text {EM max }}$ (Fig. 4) was determined while working the soil at the speeds of $2.5 \mathrm{~m} / \mathrm{s}$ to $3.5 \mathrm{~m} / \mathrm{s}$, with the soil rolling resistance ratio $f_{\text {roll }}=0.18$. During acceleration, the load varied from 0 to $80 \mathrm{kN}$.
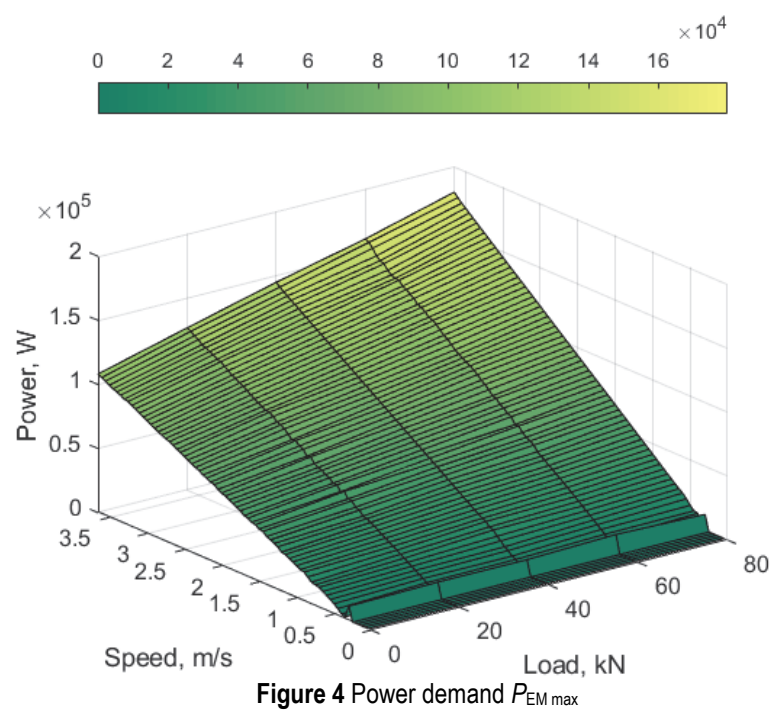

The difference of the maximum power under $80 \mathrm{kN}$ load at the highest versus lowest operating speeds was 53 $\mathrm{kW}$ (minimum value: $133 \mathrm{~kW}$, maximum value: $186 \mathrm{~kW}$ ). The difference in power demand at the same speeds under $20 \mathrm{kN}$ is $39 \mathrm{~kW}$. In this case, $133 \mathrm{~kW}$ power is consumed in gathering $3.5 \mathrm{~m} / \mathrm{s}$ operating speed, $94 \mathrm{~kW}-$ at $2.5 \mathrm{~m} / \mathrm{s}$ speed. The same difference in power was determined in seeking the lowest operating speed under the lowest versus highest load.

With $40 \mathrm{kN}$ load exceeded, the power demand was observed to exceed the capacities of the generator when accelerating at $3.5 \mathrm{~m} / \mathrm{s}$; hence, the power demand was not met when using a directly connected series-hybrid drive.

The power demand for work without acceleration was calculated theoretically, using the same initial data as in the mathematical model. The calculation results are presented in Fig. 5.

It was determined that, in all working modes, power consumption was approximately $70 \%$ lower than during acceleration. The non-correspondence varied from $-0.14 \%$ to $0.49 \%$. Reliability of the model was verified according to the power deviation (Tab. 3).

The determined highest power demand for the work was $131 \mathrm{~kW}$. Nonetheless, considering that that speed of work was infeasible at the acceleration chosen, maximum working power at the working speed developed was assessed. The result was $112 \mathrm{~kW}$ at $2.5 \mathrm{~m} / \mathrm{s}$ working speed under $80 \mathrm{kN}$ load and $106 \mathrm{~kW}$ at $3.5 \mathrm{~m} / \mathrm{s}$ speed under 40 
$\mathrm{kN}$ load. The lowest power demand for work in the case analysed: $66 \mathrm{~kW}$ at $2.5 \mathrm{~m} / \mathrm{s}$ speed under $20 \mathrm{kN}$ load.

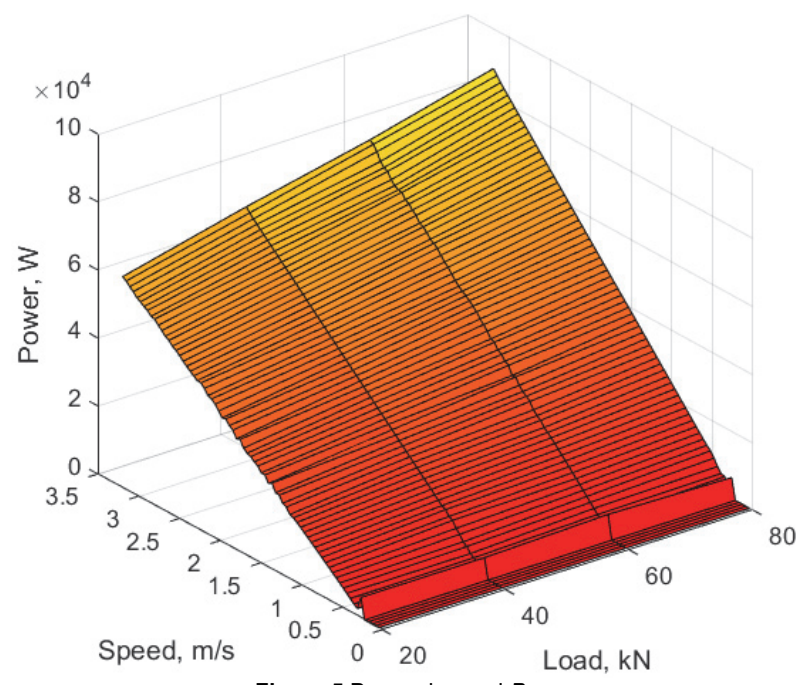

Figure 5 Power demand $P_{\text {EM work }}$

In order to assess the drive efficiency, the power range commonly used for work of the drive must be determined. For this purpose, the graph of the power frequencies was designed based on the points of the results for the power demand in the work modes analysed (Fig. 6).

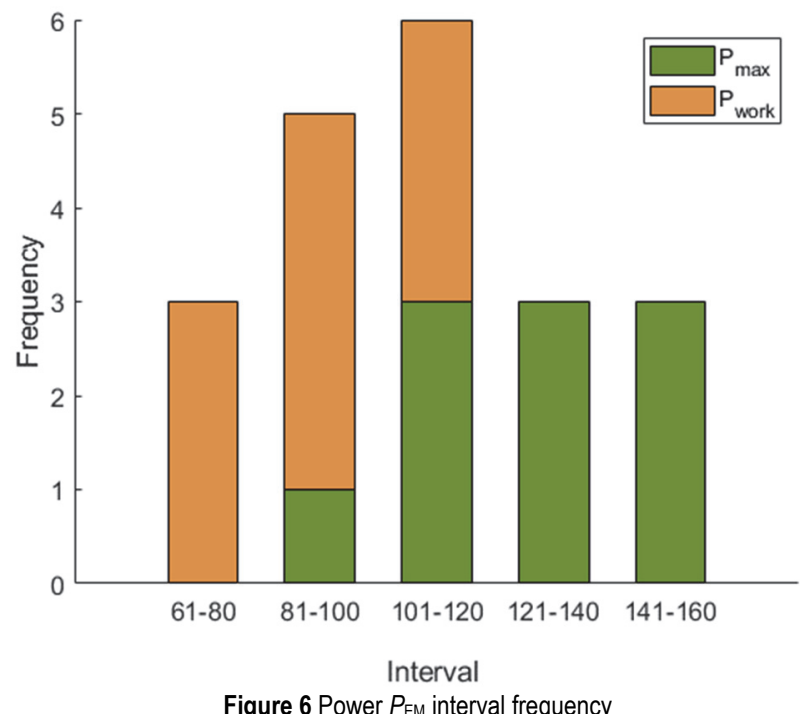

Of the 20 cases assessed (excluding the results beyond the capacities of the hybrid drive), $101 \mathrm{~kW}$ to $120 \mathrm{~kW}$ power was usually consumed, 3 cases for acceleration and work, each. $81 \mathrm{~kW}$ to $100 \mathrm{~kW}$ power was also consumed more often: for this range, in 4 cases of 5 , power was consumed for the work.

Following comparison of the electric motor power $P_{\text {EM work }}$ and the ICE power output $P_{\text {ICE work, power loss } \delta \text { in }}$ the drive was calculated. Whereas, in this case, direct transfer of power without energy storage and output at the required moment was assessed, the ICE work in the highest efficiency zone was not secured. The loss in the drive varied from $7.9 \%$ at $3.0 \mathrm{~m} / \mathrm{s}$ speed under $20 \mathrm{kN}$ load to $15.3 \%$ at $3.5 \mathrm{~m} / \mathrm{s}$ speed under $20 \mathrm{kN}$ load. All the results are presented in Tab. 1.

Following the calculation of power loss of the hybrid drive, assessment of efficiency $\eta$ of the hybrid drive was performed: the results were classified by speed and load, the means and errors of the efficiency ratios were determined. The mean of the efficiency ratio was also determined according to the frequencies of the power demand intervals (Fig. 6). The work modes not performed by the hybrid tractor were excluded from the assessment in determination of the drive efficiency.

\begin{tabular}{|c|c|c|c|}
\hline Speed, $\mathrm{m} / \mathrm{s}$ & Load / kN & $P_{\mathrm{ICE} \text { work }} / \mathrm{kW}$ & $\delta / \%$ \\
\hline \multirow{4}{*}{2.5} & 20 & 76 & 13.3 \\
\hline & 40 & 83 & 9.8 \\
\hline & 60 & 94 & 10.7 \\
\hline & 80 & 102 & 8.9 \\
\hline \multirow{4}{*}{3.0} & 20 & 93 & 14.6 \\
\hline & 40 & 98 & 7.9 \\
\hline & 60 & 111 & 9.0 \\
\hline & 80 & 129 & 13.3 \\
\hline \multirow{2}{*}{3.5} & 20 & 110 & 15.3 \\
\hline & 40 & 118 & 10.4 \\
\hline
\end{tabular}

The average drive efficiency (Fig. 7) differed insignificantly by power: $89 \%$ to $89.3 \%$ in 101 to $120 \mathrm{~kW}$ and 81 to $100 \mathrm{~kW}$ power intervals, respectively. In efficiency assessment by speed, the mean was observed to vary slightly and comprise $88.4 \%$, while the distribution of means at different speeds was large. Total efficiency of the drive by load also differed insignificantly and was $88.8 \%$. Individual means under $20 \mathrm{kN}, 40 \mathrm{kN}$ and $60 \mathrm{kN}$ load were also characterised by smaller dispersion of the values than the means by speed. Correlation of the results was not found in either of the groups of means. Total average of the drive efficiency was $88.7 \%$. Theoretical drive efficiency ratio: up to $92.2 \%$.

Fuel consumption for each work mode was determined using the specific fuel consumption map. Only the energy demand required from the generator at the moment was assessed without accounting for the energy storages, or by implying that they were fully discharged, and the generator energy was used for the work only. Data on the consumption provided in the model in grams per second $(\mathrm{g} / \mathrm{s})$ were recalculated into comparable fuel consumption in grams per kilowatt-hour $Q(\mathrm{~g} / \mathrm{kWh})$. Run time was also calculated for one fill of the $\mathrm{CNG}$ cylinders.

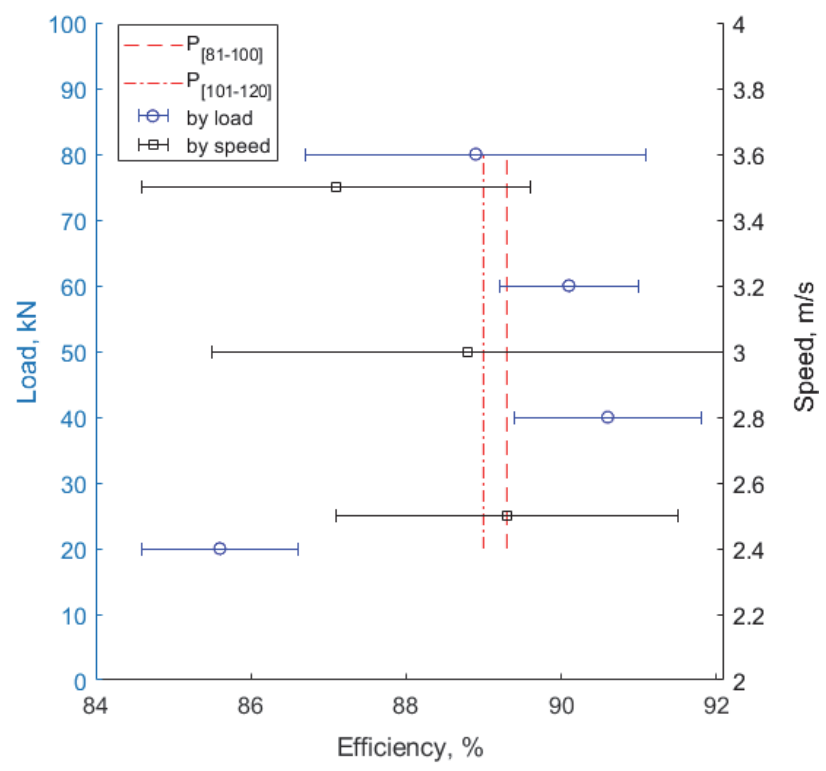

Figure 7 Hybrid drive efficiency 
In the case analysed, the relative fuel consumption decreased with the increase of work load and at the same speed of work, as the ICE work settled at the most efficient point (Tab. 2). For the same reason, the resulting relative fuel consumption was also lower under the same workloads, but at higher speed. In general, the most efficient work mode of the tractor considered and the ICE was determined at $3.0 \mathrm{~m} / \mathrm{s}$ speed under $80 \mathrm{kN}$ load $(276$ $\mathrm{g} / \mathrm{kWh}$ ); the least efficient work mode of the ICE was at $2.5 \mathrm{~m} / \mathrm{s}$ work speed under $20 \mathrm{kN}$ load (486 g/kWh). Hence, there was no considerable change in the total work duration on one full fuel cylinder at a speed varying from $2.5 \mathrm{~m} / \mathrm{s}$ to $3.5 \mathrm{~m} / \mathrm{s}$ - difference in the work duration $\mathrm{s}-0.4 \mathrm{~h} .7 .5-7.9$ $\mathrm{h}$ of work were available on one full fuel cylinder. In view of the results, to have the lowest fuel consumption and achieve the highest efficiency of the ICE, it is reasonable to optimise the powertrain management algorithm.

Table 2 Fuel consumption and work time

\begin{tabular}{|c|c|c|}
\hline Speed / m/s & Load / $\mathrm{kN}$ & $Q / \mathrm{g} / \mathrm{kWh}$ \\
\hline \multirow{4}{*}{2.5} & 20 & 486 \\
\cline { 2 - 3 } & 40 & 445 \\
\cline { 2 - 3 } & 60 & 393 \\
\cline { 2 - 3 } & 80 & 362 \\
\hline \multirow{4}{*}{3.0} & 20 & 383 \\
\cline { 2 - 3 } & 40 & 363 \\
\cline { 2 - 3 } & 60 & 321 \\
\cline { 2 - 3 } & 80 & 276 \\
\hline \multirow{3}{*}{3.5} & 20 & 318 \\
\cline { 2 - 3 } & 40 & 297 \\
\hline
\end{tabular}

For verification of reliability of the model, deviations $\sigma$ of data of the power demand for acceleration $P_{\mathrm{EM} \text { max }}$ and work $P_{\mathrm{EM} \text { work }}$ were assessed. Rounded absolute deviation values (Tab. 3) were taken and distribution of the deviations was determined (Fig. 8).
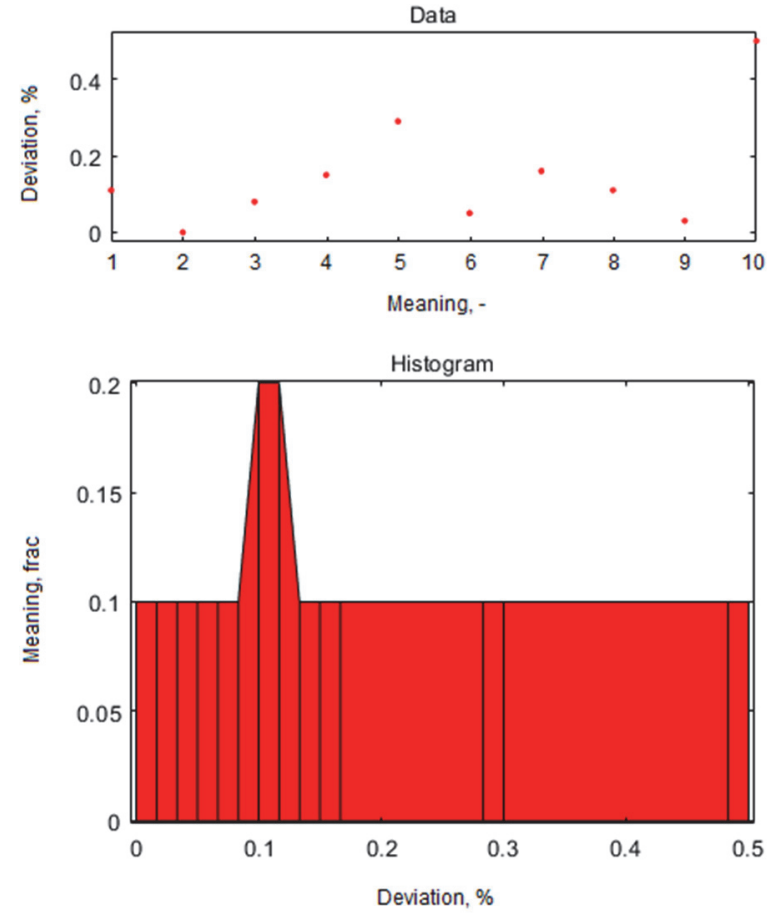

Figure 8 Data distribution

\begin{tabular}{|c|c|c|c|c|c|c|c|c|c|c|}
\hline \multicolumn{1}{|c|}{ Table 3 Data deviations } \\
\hline$\frac{P_{\text {EM work }}}{P_{\text {EM max }}} / \%$ & 70.111 & 70.004 & 69.920 & 69.853 & 70.292 & 69.946 & 70.160 & 69.894 & 70.033 & 70.496 \\
\hline$\sigma / \%$ & 0.111 & 0.004 & -0.080 & -0.147 & 0.292 & -0.054 & 0.160 & -0.106 & 0.033 & 0.496 \\
\hline$|\sigma| / \%$ & 0.11 & 0.00 & 0.08 & 0.15 & 0.29 & 0.05 & 0.16 & 0.11 & 0.03 & 0.50 \\
\hline
\end{tabular}

The determined non-correspondence of the power ratio varied from $-0.147 \%$ to $0.496 \%$. The major share of the data was concentrated within interval $0-0.16 \%$. Median of values: $0.11 \%$, mean: $0.148 \%$. Mean model calculation error: $0.15 \%$.

The investigation was performed under one of the hardest work conditions. Usually, during work under higher load $(60 \mathrm{kN}-80 \mathrm{kN}), f_{\text {roll }}$ value should be lower, while under lower load (up to $60 \mathrm{kN}$ ), resistance to rolling during work would be similar to the case analysed. Considering that work at higher speed would most usually be performed within the most efficient ICE zones, and at lower speed - under lower load, the power of the serieshybrid drive without energy reserve is sufficient to perform the majority of regular cultivation works. Nonetheless, for avoidance of the limitations due to the difficult work conditions and to improve efficiency of the drive and reduce the work costs, a unit capable of storing large energy reserve shall be installed and used. This should reduce the determined drive losses, which, at present, do not virtually differ from the usual continuously variable transmission losses used in these tractors.

\section{CONCLUSIONS}

The paper presents a numerical hybrid tractor model enabling investigation of the hybrid drive characteristics during the field works by assessment of the work conditions: work speed, load, nature of soil. The model may be used for development and optimisation of the management algorithms for series-hybrid agricultural machinery powertrains.

Energy losses of the hybrid drive in the case analysed - during soil cultivation - depended highly on the ICE work point efficiency, and the variation of the difference between the lowest and highest loss was almost two-fold.

The mean $89 \%$ efficiency of the drive was achieved during modelling.

The initially set most difficult work conditions were found to not be fully feasible using only the electric energy generated at the particular moment, and this case is highly probable during soil works due to very scarce possibilities for energy recovery. To achieve the highest $3.5 \mathrm{~m} / \mathrm{s}$ work speed under a work load greater than $40 \mathrm{kN}$, energy reserve was needed and, consequently, high capacity energy storage had to be used. Energy of the generator was sufficient under less difficult work conditions, and the drive was fully applicable to the agricultural works.

Powertrain management was found to be a crucial determinant of the fuel consumption. If the work of the $\mathrm{CNG}$ engine is not secured in the most efficient modes, this may result in higher fuel consumption during tractor work under lower load. 
The results generated by the numerical model did not differ considerably from the theoretical mathematical calculations. The mean non-correspondence of the results was $0.15 \%$. The accuracy of the numerical model designed was sufficient.

\section{REFERENCES}

[1] Peterson, M., Barter, G., West, T., \& Manley, D. (2014). A parametric study of light-duty natural gas vehicle competitiveness in the United States through 2050. Applied Energy, 125(C), 206-217. https://doi.org/10.1016/j.apenergy.2014.03.062

[2] Kluschke, P., Gnann, T., Plötz, P., \& Wietschel, M. (2019). Market diffusion of alternative fuels and powertrains in heavy-duty vehicles: A literature review. Energy Reports, 5, 1010-1024. https://doi.org/10.1016/j.egyr.2019.07.017

[3] Baek, D., Chen, Y., Chang, N., Macii, E., \& Poncino, M. (2020). Optimal Battery Sizing for Electric Truck Delivery. Energies, 13(3), 709. https://doi.org/10.3390/en13030709

[4] Brito, F. P., Martins, J., Lopes, F., Castro C., Martins, L., \& Moreira, A. L. N. (2020). Development and Assessment of an Over-Expanded Engine to be used as an EfficiencyOriented Range Extender for Electric Vehicles. Energies, 13(2), 430. https://doi.org/10.3390/en13020430

[5] Smallbone, A., Jia, B., Atkins, P., \& Roskilly, A. (2020). The impact of disruptive powertrain technologies on energy consumption and carbon dioxide emissions from heavy-duty vehicles. Energy Conversion and Management: X, 6(6). https://doi.org/10.1016/j.ecmx.2020.100030

[6] Anderhofstadt, B. \& Spinler, S. (2020). Preferences for autonomous and alternative fuel-powered heavy-duty trucks in Germany. Transportation Research Part D, 79. https://doi.org/10.1016/j.trd.2020.102232

[7] Bahrami, S., Nourinejad, M., Amirjamshidi, G., \& Roorda, M. (2020). The Plugin Hybrid Electric Vehicle routing problem: A power-management strategy model. Transportation Research Part C, 111, 318-333. https://doi.org/10.1016/j.trc.2019.12.006

[8] Kim, D.-M., Benoliel, P., Kim, D.-K., Lee, T. H., Park, J. W., \& Hong, J.-P. (2019). Framework Development of Series Hybrid Powertrain Design for Heavy-Duty Vehicle Considering Driving Conditions. IEEE Transactions on Vehicular Technology, 68(7), 6468-6480. http://doi.org/10.1109/TVT.2019.2914868

[9] Mayet, C., Welles, J., Bouscayrol, A., Hofman, T., \& Lemaire-Semail, B. (2019). Influence of a CVT on the fuel consumption of a parallel medium-duty electric hybrid truck. Mathematics and Computers in Simulation, 158, 120-129. https://doi.org/10.1016/j.matcom.2018.07.002

[10] Peng, H., Qin, D., Hu, J., \& Fu, C. (2020). Synthesis and analysis method for powertrain configuration of single motor hybrid electric vehicle. Mechanism and Machine Theory, 146. https://doi.org/10.1016/j.mechmachtheory.2019.103731

[11] Pitla, S., Luck, J., Werner, J., Lin, N., \& Shearer, S. (2016). In-field fuel use and load states of agricultural field machinery. Computers and Electronics in Agriculture, 121(C), 290-300. https://doi.org/10.1016/j.compag.2015.12.023

[12] Moitzi, G., Haas, M., Wagentristl, H., Boxberger, J., \& Gronauer, A. (2013). Energy consumption in cultivating and ploughing with traction improvement system and consideration of the rear furrow wheel-load in ploughing. Soil \& Tillage Research, 134, 56-60. https://doi.org/10.1016/j.still.2013.07.006

[13] Bührke, J., Schramm, F., \& Frerichs, L. (2018). Geometriediskrete Belastungsmessung an einem Grubber Werkzeug. LANDTECHNIK, 73(2), 39-51. https://doi.org/10.15150/lt.2018.3181

\section{Contact information:}

Ugnè Koletė MEDŽEVEPRYTĖ, PhD

(Corresponding author)

Kaunas University of Technology,

Studentu 56, 51424, Kaunas, Lithuania

E-mail: ugne.medzevepryte@ktu.lt

Rolandas MAKARAS, Assoc. Prof

Kaunas University of Technology,

Studentu 56, 51424, Kaunas, Lithuania

E-mail: rolandas.makaras@ktu.lt

Vaidas LUKOŠEVIČIUS, Prof

Kaunas University of Technology,

Studentu 56, 51424, Kaunas, Lithuania

E-mail: vaidas.lukosevicius@ktu.It

Artūras KERŠYS, Prof

Kaunas University of Technology,

Studentu 56, 51424, Kaunas, Lithuania

E-mail: arturas.kersys@ktu.It 